\title{
Inhaltsverzeichnis Band 8
}

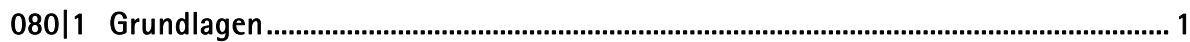

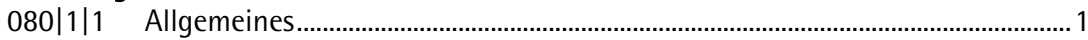

$080|1| 2 \quad$ Konstruktionsprinzipien ...................................................................................

$080|1| 3 \quad$ Wasserableitung .............................................................................................. 4

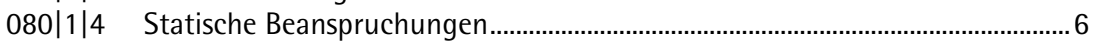

$080|1| 4 \mid 1 \quad$ Eigengewicht .................................................................................. 6

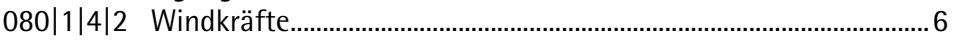

$080|1| 4 \mid 3$ Schneelasten .............................................................................. 12

$080|1| 4 \mid 4$ Nutzlasten .....................................................................................14

$080|1| 5 \quad$ Brandschutz .....................................................................................................14

080|1|6 Absturzsicherungen ........................................................................................14

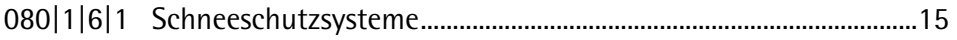

$080|1| 6 \mid 2$ Personenschutzsysteme.................................................................16

$080|1| 6 \mid 3$ Rauchfangkehrerstege ................................................................16

080|1|7 Photovoltaik, Solar..........................................................................................

$080|1| 8 \quad$ Vorschriften ...................................................................................................... 17

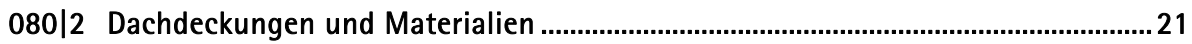

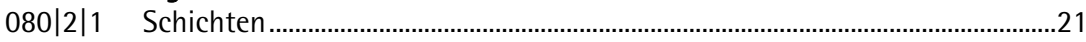

$080|2| 1 \mid 1 \quad$ Dachdeckungen ..................................................................................22

$080|2| 1 \mid 2$ Konterlattung, Lattung, Schalung................................................22

$080|2| 1 \mid 3$ Abdichtungen, Unterdach, Unterspannbahn ...............................24

$080|2| 1 \mid 4$ Wärmedämmung ..............................................................................27

$080|2| 1 \mid 5$ Tragkonstruktion ........................................................................

$080|2| 1 \mid 6$ Dampfbremsen, Dampfsperren......................................................32

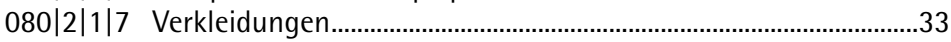

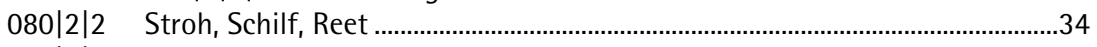

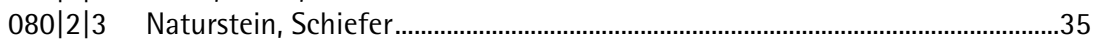

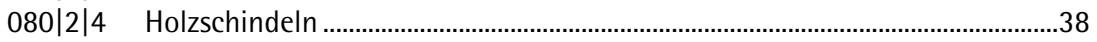

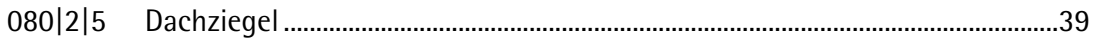

$080|2| 5 \mid 1$ Plattenziegel ........................................................................................40

$080|2| 5 \mid 2$ Hohlziegel ................................................................................... 43

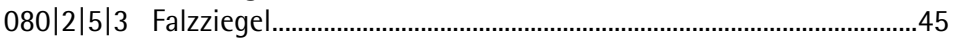

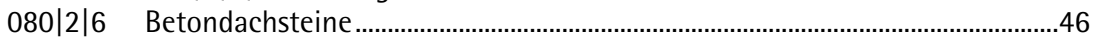

$080|2| 7 \quad$ Faserzementplatten ...............................................................................................4

$080|2| 7 \mid 1 \quad$ Faserzement-Tafeldeckung..............................................................4

$080|2| 7 \mid 2$ Faserzement-Wellplattendeckung.................................................49

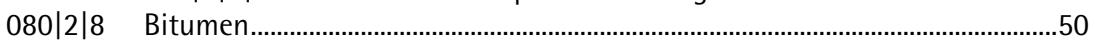

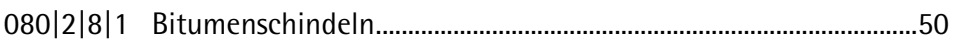

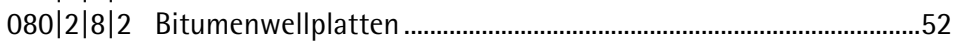

080|2|9 Gläser und Kunststoffe.................................................................................53

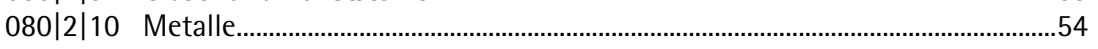

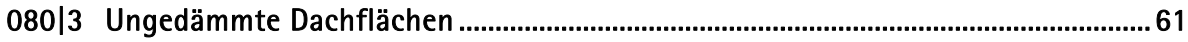

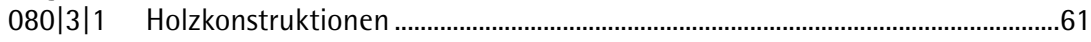

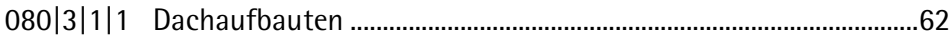

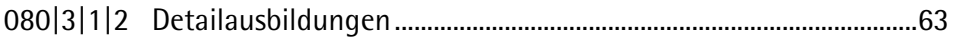

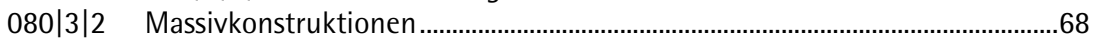

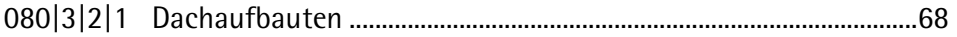

$080|3| 3$ Metallkonstruktionen.......................................................................................68

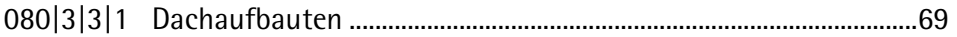

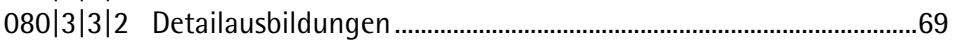


080|4 Gedämmte Dachflächen ....................................................................................... 71

$080|4| 1 \quad$ Wärmedämm- und Hinterlüftungsebenen ..........................................................71

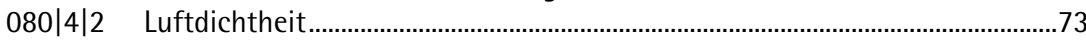

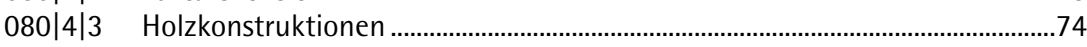

$080|4| 3 \mid 1 \quad$ Dachaufbauten ....................................................................................

$080|4| 3 \mid 2$ Detailausbildungen ..........................................................................77

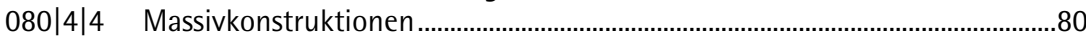

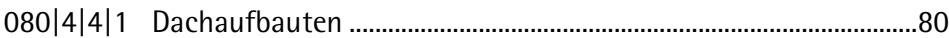

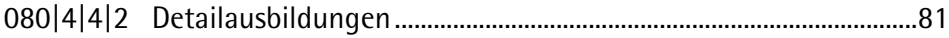

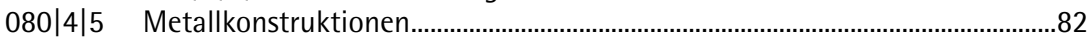

$080|4| 5 \mid 1 \quad$ Dachaufbauten ..................................................................................83

$080|4| 5 \mid 2$ Detailausbildungen .............................................................................84

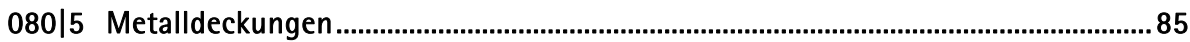

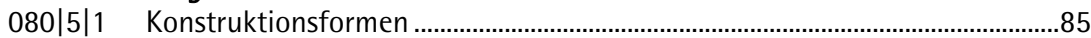

$080|5| 1 \mid 1 \quad$ Bahnendeckung - nicht tragend ....................................................85

$080|5| 1 \mid 2$ Bahnen- oder Tafeldeckung - tragend ...........................................86

$080|5| 1 \mid 3$ Vorgefertigte Dacheindeckungsprodukte - Dachplatten............86

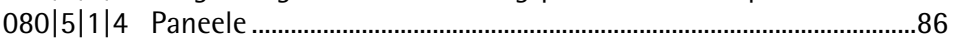

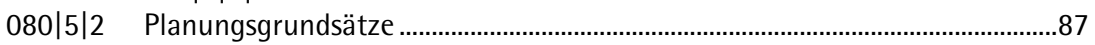

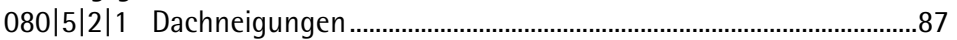

$080|5| 2 \mid 2$ Thermische Längenänderungen - die freie Verformbarkeit .......88

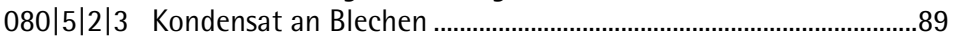

$080|5| 2 \mid 4 \quad$ Korrosion und elektrochemische Korrosion.....................................89

$080|5| 2 \mid 5$ Schall und Lärm .............................................................................91

$080|5| 2 \mid 6$ Trennlagen..........................................................................................91

$080|5| 2 \mid 7$ Hinterlüftung der Dachhaut ..........................................................91

$080|5| 2 \mid 8$ Verbindungen .....................................................................................92

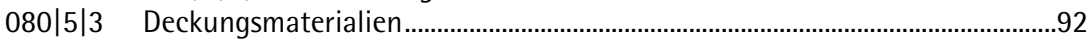

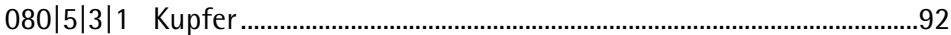

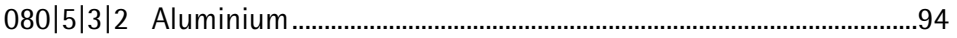

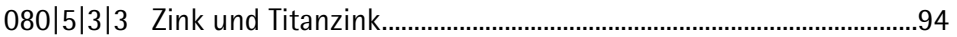

$080|5| 3 \mid 4$ Verzinkter Stahl ................................................................................95

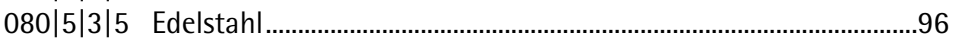

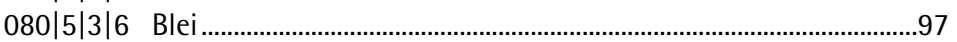

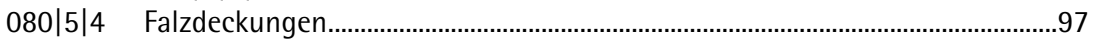

080|5|4|1 Traditionelles Stehfalzdach ..............................................................97

$080|5| 4 \mid 2$ Vorgefertigte Falze und Falzblechdächer.......................................98

$080|5| 4 \mid 3 \quad$ Falze und Falzarten ...........................................................................98

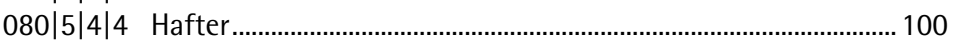

080|5|5 Schnappfalz-, Gleitbügel- und Klemmleistensysteme .................................... 101

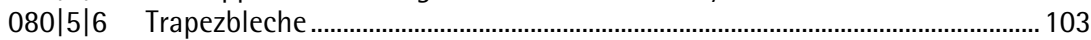

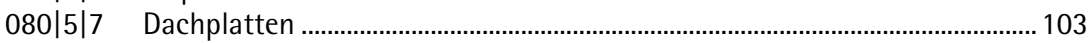

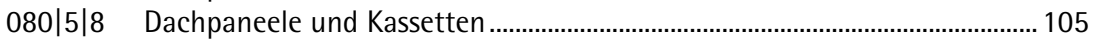

080|5|9 Spezielle Anschlüsse bei Metalldeckungen....................................................... 106

$080|5| 9 \mid 1$ Durchdringungen .......................................................................... 106

080|5|9|2 Falzklemmen, Schneerechen …………............................................ 106

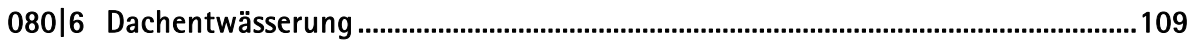

080|6|1 Bemessung Dachentwässerung ........................................................................ 109

$080|6| 1 \mid 1$ Bemessungsniederschläge................................................................ 109

$080|6| 1 \mid 2$ Abflussbeiwert............................................................................... 110

$080|6| 1 \mid 3$ Wirksame Dachfläche...................................................................... 111

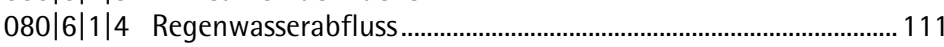

080|6|1|5 Abflussvermögen der Bauelemente .............................................. 111 
080|6|2 Bauelemente.......................................................................................... 113

$080|6| 2 \mid 1$ Regenfallrohre................................................................................ 114

$080|6| 2 \mid 2$ Hängerinnen ............................................................................... 116

$080|6| 2 \mid 3$ Saumrinnen....................................................................................... 118

$080|6| 2 \mid 4$ Standrinne, Kastenrinne, Attikarinne ............................................ 120

$080|6| 2 \mid 5$ Innenliegende Rinnen .................................................................... 121

$080|6| 2 \mid 6$ Kehlrinnen (Ichsenrinnen)........................................................... 121

$080|6| 2 \mid 7$ Giebeleinfassungen, Ortgangrinnen .......................................... 122

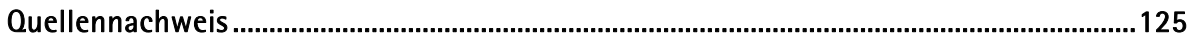

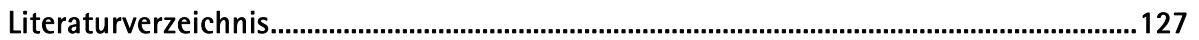

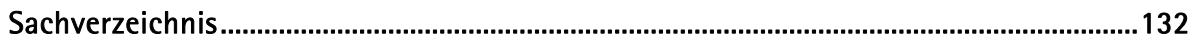


